International Journal of Civil Engineering and Technology (IJCIET)

Volume 9, Issue 6, June 2018, pp. 793-799, Article ID: IJCIET_09_06_091

Available online at http://www.iaeme.com/ijciet/issues.asp?JType=IJCIET\&VType=9\&IType $=6$

ISSN Print: 0976-6308 and ISSN Online: 0976-6316

(C) IAEME Publication

Scopus Indexed

\title{
ONLINE SHOPPERS ACCEPTANCE: AN EXPLORATORY STUDY
}

\author{
Muhammad Dharma Tuah Putra Nasution, Yossie Rossanty, Pipit Buana Sari and \\ Andysah Putera Utama Siahaan
}

Universitas Pembangunan Panca Budi, Indonesia

\begin{abstract}
Consumers are increasingly easy to access to information resources. Consumers quickly interact with whatever they will spend. Ease of use of technology an impact on consumer an attitude are increasingly intelligent and has encouraged the rise of digital transactions. Technology makes it easy for them to transact on an e-commerce shopping channel. Future e-commerce trends will lead to User Generated Content related to user behavior in Indonesia that tends to compare between shopping channels. The purpose of this study was to examine the direct and indirect effects of Perceived Ease of Use on Behavioral Intention to transact in which Perceived Usefulness is used as an intervening variable. The present study used the descriptive exploratory method with causal-predictive analysis. Determination method of research sample used purposive sampling. The enumerator team assists in the distribution of questionnaires. The results of the study found that the direct effect of perceived ease of use on behavioral intention to transact is smaller than that indirectly mediated by perceived usefulness variables.
\end{abstract}

Keywords: TAM, Perceived Ease of Use, Perceived Usefulness, Behavioral Intention to transact, E-Commerce.

Cite this Article: Muhammad Dharma Tuah Putra Nasution, Yossie Rossanty, Pipit Buana Sari and Andysah Putera Utama Siahaan, Online Shoppers Acceptance: An Exploratory Study, International Journal of Civil Engineering and Technology, 9(6), 2018, pp. 793-799

http://www.iaeme.com/IJCIET/issues.asp?JType=IJCIET\&VType=9\&IType=6

\section{INTRODUCTION}

Advancements in use of information technology and use of the internet for business transactions are still under scrutiny in recent studies. The Internet is an electronic medium that is used for various activities such as communication, research, and business transactions. Internet use for business transactions is acknowledged by Electronic Commerce [1].

The characteristics of e-commerce concerning transactions between two parties; the exchange of goods, services, or information, and the Internet as the primary medium in the transaction process. One form of e-commerce is Business to Consumer (B2C). B2C is e- 
commerce whom people in business transact selling and buying products or services directly to consumers without intermediaries, such as distributors and agents. How a model has explained consumer behavior in adopting a technology termed Technology Acceptance Model (TAM). TAM model is based on Theory of Reason Action (TRA). TRA explains why individuals adopt technology because they can benefit users. There are two central concepts that consumers highlight, namely perceived usefulness and perceived ease of use [2]. Perceived Ease of Use (PEOU) is the level of confidence that a person is using a system will be free from difficulty effort [3]. Meanwhile, Perceived Usefulness (PU) is a level of confidence in the technology that will be used to improve performance. In this case, the consumers will receive the benefit of using the online service site if the consumer's perception feels accepting ease in the operation of the online service site. Perceived Ease of Use and Perceived Usefulness will affect consumer's intention to transact. Researchers [4] interpreting intention to transactions is the desire of consumers to engage in online exchange relationships with Web retailers, such as sharing information, maintaining business relationships, and conducting business transactions. Beginning by [3] who have found a relationship with Perceived Ease of Use (PEOU), Perceived Usefulness (PU) and intention to use. However, [5] stated that there is no evidence to suggest a direct effect between Perceived Ease of Use (PEOU) on intention to transact. Until now TAM has been able to recognize the high and low behavioral intention to use or transaction. Perceived ease of use (PEOU) and perceived usefulness (PU), are two perceptions that affect the high intention to transact [6] [7] [8].

\section{LITERATURE REVIEW}

\subsection{Online Transactions}

Internet as a medium of a transaction or more often known as e-commerce. E-commerce has provided considerable benefits in accessing new markets, encouraging innovation, more efficient supply and distribution management and improved customer service. Transactions made through e-commerce combine online ordering and payments. Online transactions defined by [9] as consumers desire to be tied to web marketers via the internet such as sharing business information, establishing cooperative relationships, and conducting business transactions. Online transactions have several distinctive features that are different from traditional transactions. The differences referred to [9] include the extensive use of technology for transactions; the distant and impersonal nature of the online environment; the inherent uncertainty of using an open technological infrastructure for a transaction.

\subsection{Technology Acceptance Model (TAM)}

TAM has been widely used in various studies and verified in different situations, conditions, and different objects to assess individual behavior in technology acceptance [10]. TAM is considered most relevant in predicting the desire as well as the readiness to adopt the technology [11]. The study of [6] describes TAM undergoing modification and development. In 2000, the constructs of the attitude towards usage were eliminated, which means that the constructs of perceived usefulness and perceived ease of use have a direct effect on behavioral intention to use. The continued development of TAM was recorded in 2008 by adding a new dimension to the PEOU construct. The development of TAM is intended to form basic assumptions that are capable of predicting, and explaining the concept of behavior caused by technological developments [3] [2]. How does the concept of individual behavior over technological developments whether accepting or rejecting in the utilization of technology [12] [13]? Until now the scholars, e.g. [13] [11] consider TAM still relevant predict the desire 
and readiness to adopt the technology. The explanation is affirmed by [6] who mentions TAM is still relevant to interpret the readiness of users in utilizing information technology.

\subsection{Perceived Ease of Use (PEOU)}

Perceived ease of use is defined as the extent to which users expect the use of technology to have no difficulty in learning and applying the technology [14] [8] [15]. The perception of individuals using new technology will be free from hardship and endeavor. Scholars such as [16] [17] agreed on perceived ease of use as a consumer perception that shopping on the internet would involve only minimal effort. As for other scholars [7] suggests that Perceived ease of use (PEOU) emphasizes the use of information technology systems and applications. Perceived ease of use (PEOU) is defined as the level of confidence in the use of technology, the degree of confidence that to apply technology requires no great effort in its use or application. The more difficult it is to use technology, the less desire to use it [18]. When the individual assesses the technology is easy to use, then he or she will know its utilization of work activities. In other words, the level of perception of ease to use the technology will affect the perceived usefulness of the technology. The more comfortable technology is used then the higher the interest of the individual to [19]. The more difficult the technology is used has an impact on the lower interest of individuals to use or adopt technology[20] [21]. Perceived ease of use (PEOU) is associated with the ease of use of the Internet perceived consumers for various goals to be achieved [5]. The study by [22] Perceived ease of use (PEOU) is defined as the degree to which a person believes that using a particular system would enhance his or her job performance. The study by [23] proves that perceived ease of use (PEOU) affects perceived usefulness (PU). The desire to apply technology or not depends on the level of ease in learning about usage. Explanation of [24] [25] explains the more difficult the technology is used, the lower the individual's interest to adopt and transact. Similar to previous researchers [26] the more comfortable technology used, the higher the individual's interest to transact.

\subsection{Perceived Usefulness (PU)}

Perceived usefulness (PU) has been one of the dominant factors that shape the desired behavior to use the technology. Perceived usefulness is defined as an assessment of the prospective originating from a personal perspective, which by using a particular application system will improve the quality of work and quality of life, confidence by using the application will improve his performance [12]. Another definition expressed by [18] [3] perceived usefulness is the extent to which a person believes by using information technology will improve the workability of the users. As for [23] convey that people tend to use or not to depend on the extent to which the level of trust that the application supports individuals work faster or vice versa. Perceived usefulness is one of the dominant factors that cultivate the desire to use technology due to expectations of improved performance [15]. Furthermore [5] states that Perceived usefulness (PU) identifies the various benefits consumers receive from using the Internet to make transactions. Perceived usefulness (PU) is defined as the degree to which a person believes that using a particular system would be free of effort [27]. Several prior studies such as [23] and [25] suggest Perceived usefulness (PU) had an influence on Behavioral Intention. Scholar [6] describes Perceived usefulness (PU) had an influence on Behavioral Intention. Similarly, researchers [23] concluded, Perceived usefulness (PU) had a direct impact on intention to use. Therefore, the existence of Perceived usefulness (PU) directly affects behavioral intentions to transact. 


\section{Muhammad Dharma Tuah Putra Nasution, Yossie Rossanty, Pipit Buana Sari and Andysah Putera Utama Siahaan}

\subsection{Behavioral intention to transact (BIT)}

Several scholars define behavioral intention as a measure of a person's probability of using an app [12]. Other scholars like [28] [29] define Behavioral intention as a measure of one's desire to perform certain behaviors. Research conducted by [30] defines behavioral intention as a subjective probability of a person that he or she will perform some behavior

The findings [30] prove intent or desire to behave for the adoption of new technologies dominated by PEOU and Perceived usefulness (PU) compared to subjective norms.

Researchers [30] also prove PEOU and Perceived usefulness of PU have a positive effect on intention to use. While the researcher [5] defines behavioral intention is the tendency of desire and consumer interest in using the internet to transact. Similarly, [4] suggests an intention to transact as the consumer's intention to engage in online exchange relationships with Web retailers, such as sharing information, maintaining business relationships, and conducting business transactions.

\section{RESEARCH METHOD}

The present study used a descriptive exploratory method which aims to describe the situation or phenomenon that is intended for causal-predictive analysis [31]. Determination method of research sample used purposive sampling to the students at Universitas Pembangunan Panca Budi. Determination of sample is based on predetermined criteria. Methods Data collection through questionnaire distribution. The enumerator team assists in the distribution of questionnaires. From questionnaires distributed to 100 participants, there was one incomplete questionnaire. Therefore it is concluded the number of participants in this study amounted to 99 samples. The measurement scale of variables in this research is using the Semantic Differential scale.

\section{RESULTS \& DISCUSSION}

The first hypothesis (H1) Perceived ease of use affects Behavioral intention to transact.

The t-count value for the perceived ease of use variable is 3.484 which is higher than the value of the t-table is 1.661 , or the significance value of perceived ease of use is .001 is smaller than the 5\% alpha. Thus the first hypothesis of the study found that perceived ease of use has a positive and significant effect on behavioral intention to transact in e-commerce can be proven and accepted.

The second hypothesis (H2) Perceived ease of use affects perceived usefulness.

The t-count value for the perceived ease of use variable is 2.011 which is higher than the t-table value is 1.661 , with the significance value for the perceived ease of use variable is 0.047 and less than the alpha of 5\% (0.05). Thus, the second hypothesis of the study shows that perceived ease of use has a positive and significant effect on perceived usefulness proven and supported.

Table 1 Result of Hypotheses Test

\begin{tabular}{|c|c|c|c|c|c|}
\hline Hypothesis & & $\begin{array}{c}\text { Standardized } \\
\text { Coefficients } \\
\text { Beta }\end{array}$ & t-value & Sig-t & $\mathbf{R}^{\mathbf{2}}$ \\
\hline (H1) & PEOU to BIT & .333 & 3.484 & .001 & .102 \\
\hline (H2) & PEOU to PU & .200 & 2.011 & .046 & .030 \\
\hline \multirow{2}{*}{$(\mathrm{H} 3)$} & PEOU to BIT & .045 & 3.000 & .003 & .150 \\
\cline { 2 - 6 } & PU to BIT & .242 & 2.541 & .013 & .150 \\
\hline
\end{tabular}


The third hypothesis H3: Perceived ease of use affects behavioral intention to transact with perceived usefulness as a mediating variable.

The standardized coefficients value of perceived ease of use is 0.200 and significant at 0.047 which means perceived ease of use affects perceived usefulness. The value of this standardized coefficient $(0.200)$ is the path value of $\mathrm{P} 2$. The standardized coefficients value of perceived ease of use is 0.045 . The value of standardized coefficients perceived ease of use is the path value of $\mathrm{P} 1$. The standardized coefficients value of perceived usefulness is 0.242 . The value of standardized coefficients is the path value of $\mathrm{P} 3$.

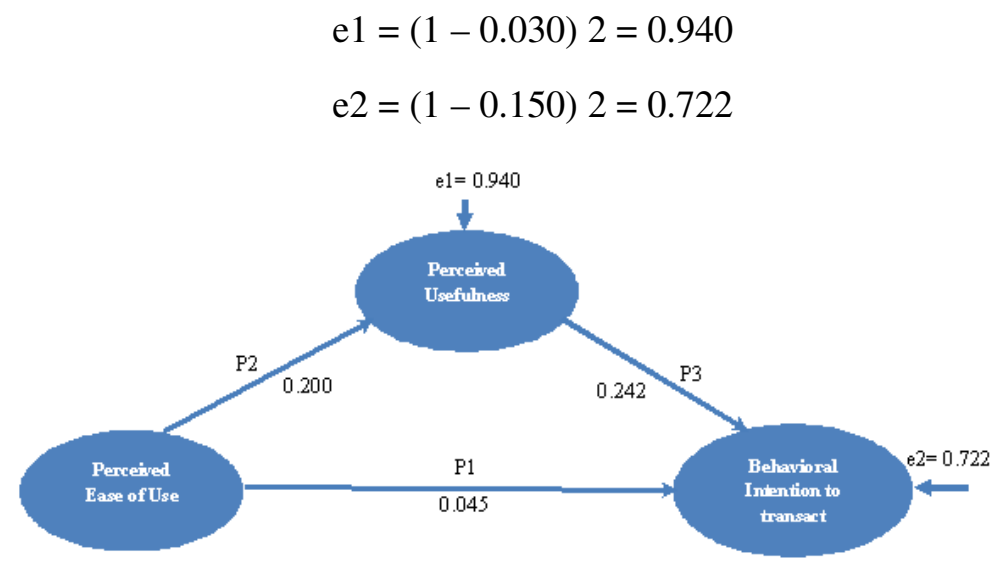

Figure 1 Research Model

The magnitude of the direct effect of perceived ease of use on behavioral intention to transact is 0.045 . While the indirect effect is calculated by multiplying the indirect coefficient: $(0.200) \times(0.242)=0.048$. The result shows that indirect influence through perceived usefulness is higher than the direct effect on behavioral intention to transact. Conclusion means perceived usefulness is a variable that mediates between perceived ease of use toward behavioral intention to transact. Thus the third hypothesis is proved and supports the previous study.

\section{CONCLUSION}

The purpose of this study was to examine the direct and indirect effects of PEOU on Behavioral Intention to transact where Perceived Usefulness (PU) is used as an intervening variable. It is concluded that the direct effect of perceived ease of use on behavioral intention to transact is smaller than the indirect influence of perceived usefulness-mediated indirect. Technology has changed the way business done mainly in the retail sector. Nowadays consumers are increasingly easy to access to information resources. Consumers quickly interact with whatever they will spend. The ease of use of technology has an impact on the attitude of consumers who know better what they want. Consumers are becoming savvier in the use, utilization, and adoption of technology and have encouraged the rise of digital transactions. Technology makes it easy to transact on e-commerce shopping channels like Lazada, Zalora, Bukalapak. Future e-commerce trends will lead to User Generated Content related to user behavior in Indonesia that tends to compare between shopping channels.

\section{ACKNOWLEDGMENTS}

The authors gratefully acknowledge the financial support from Universitas Pembangunan Panca Budi, and we would like to thank the anonymous reviewers for their comment on this article. 


\section{REFERENCES}

[1] R. Mcleod Jr and G. P. Schell, Management Information Systems. Prentice Hall, 2004.

[2] V. Venkatesh and F. D. Davis, "Studies Linked references are available on JSTOR for this article: A Theoretical Extension of the Technology Acceptance Model: Four Longitudinal Field Studies," vol. 46, no. 2, pp. 186-204, 2000.

[3] F. D. Davis, "Perceived Usefulness, Perceived Ease of Use, and User Acceptance of Information Technology," MIS Q., vol. 13, no. 3, p. 319, 1989.

[4] P. a. Pavlou, "Consumer Acceptance of Electronic Commerce: Integrating Trust and Risk with the Technology Acceptance Model," Int. J. Electron. Commer., vol. 7, no. 3, pp. 69103, 2003.

[5] H. Lui and R. Jamieson, "Integrating trust and risk perceptions in business-to-consumer electronic commerce with the technology acceptance model," Conf. Inf. Syst., no. January 1993, 2003.

[6] A. Alomary and J. Woollard, "How Is Technology Accepted by Users? A Review of Technology Acceptance Models and Theories," IRES 17th Int. Conf., no. November, pp. $1-4,2015$.

[7] V. Venkatesh and H. Bala, "Technology acceptance model 3 and a research agenda on interventions," Decis. Sci., vol. 2, no. 273-315, pp. 273-315, 2008.

[8] A. Abu Abid, M. Rahim, and H. Scheepers, "Experienced Benefits and Barriers of EBusiness Technology Adoption by SME Suppliers," Commun. IBIMA, vol. 2011, no. October 2016, pp. 1-11, 2011.

[9] P. a. Pavlou, "Integrating Trust in Electronic Commerce with the Technology Acceptance Model : Model Development and Validation," Amcis, pp. 816-822, 2001.

[10] R. A. Sánchez and A. D. Hueros, "Motivational factors that influence the acceptance of Moodle using TAM," Comput. Human Behav., vol. 26, no. 6, pp. 1632-1640, 2010.

[11] M. G. Md Johar and J. A. Ahmad Awalluddin, "The Role of Technology Acceptance Model in Explaining Effect on E-Commerce Application System," Int. J. Manag. Inf. Technol., vol. 3, no. 3, pp. 1-14, 2011.

[12] P. Surendran, "Technology Acceptance Model : A Survey of Literature," Int. J. Bus. Soc. Res., vol. 2, no. 4, pp. 175-178, 2012.

[13] M. Chuttur, "Overview of the Technology Acceptance Model: Origins, Developments and Future Directions,” Sprouts Work. Pap. Inf. Syst., vol. 9, no. 2009, pp. 1-23, 2009.

[14] D. A. Adams, R. R. Nelson, and P. A. Todd, "Perceived Usefulness, Ease of Use, and Usage of Information Technology: A Replication,” MIS Q., vol. 16, no. 2, p. 227, 1992.

[15] S.-C. Chen, S.-H. Li, and C.-Y. Li, "Recent Related Research in Technology Acceptance Model: A Literature Review,” Aust. J. Bus. Manag. Res., vol. 1, no. 9, pp. 124-127, 2011.

[16] W. M. Lim and D. H. Ting, "E-shopping: An analysis of the technology acceptance model," Mod. Appl. Sci., vol. 6, no. 4, pp. 49-62, 2012.

[17] S. L. Jarvenpaa, N. Tractinsky, and M. Vitale, "Consumer trust in an internet store," Inf. Technol. Manag., vol. 1, no. 1-2, pp. 45-71, 2000.

[18] M. Turner, B. Kitchenham, P. Brereton, S. Charters, and D. Budgen, "Does the technology acceptance model predict actual use? A systematic literature review," Inf. Softw. Technol., vol. 52, no. 5, pp. 463-479, 2010.

[19] A. Khan and J. M. Woosley, "Comparison of Contemporary Technology Acceptance Models and Evaluation of the Best Fit for Health Industry Organizations .," Int. J. Comput. Sci. Eng. Technol., vol. 1, no. 11, pp. 709-717, 2011. 
[20] X. Tong, "A cross-national investigation of an extended technology acceptance model in the online shopping context," Int. J. Retail Distrib. Manag., vol. 38, no. 10, pp. 742-759, 2010.

[21] S. Pan and M. Jordan-Marsh, "Internet use intention and adoption among Chinese older adults: From the expanded technology acceptance model perspective," Comput. Human Behav, vol. 26, no. 5, pp. 1111-1119, 2010.

[22] R. Saadé and B. Bahli, "The impact of cognitive absorption on perceived usefulness and perceived ease of use in on-line learning: An extension of the technology acceptance model," Inf. Manag., vol. 42, no. 2, pp. 317-327, 2005.

[23] O. A. Fadare, M. B. Ibrahim, and A. Edogbanya, "A survey on perceived risk and intention of adopting internet banking," J. Internet Bank. Commer., vol. 21, no. 1, pp. 121, 2016.

[24] P. G. Schierz, O. Schilke, and B. W. Wirtz, "Understanding consumer acceptance of mobile payment services: An empirical analysis," Electron. Commer. Res. Appl., vol. 9, no. 3, pp. 209-216, 2010.

[25] L. V. Casaló, C. Flavián, and M. Guinalíu, "Determinants of the intention to participate in firm-hosted online travel communities and effects on consumer behavioral intentions," Tour. Manag, vol. 31, no. 6, pp. 898-911, 2010.

[26] D. J. Kim, D. L. Ferrin, and H. R. Rao, "A trust-based consumer decision-making model in electronic commerce: The role of trust, perceived risk, and their antecedents," Decis. Support Syst., vol. 44, no. 2, pp. 544-564, 2008.

[27] C. Y. Lin, K. Fang, and C. C. Tu, "Predicting consumer repurchase intentions to shop online," J. Comput., vol. 5, no. 10, pp. 1527-1533, 2010.

[28] B. Marakarkandy, N. Yajnik, and C. Dasgupta, "Enabling internet banking adoption: An empirical examination with an augmented technology acceptance model (TAM)," J. Enterp. Inf. Manag., vol. 30, no. 2, pp. 263-294, 2017.

[29] Y. Rossanty and M. D. T. P. Nasution, "Information Search and Intentions to Purchase: The Role of Country of Origin Image, Product Knowledge, and Product Involvement," J. Theor. Appl. Inf. Technol., vol. 96, no. 10, pp. 3075-3085, 2018.

[30] A. J. Ducey, "Predicting Tablet Computer Use: An Extended Technology Acceptance Model," 2013.

[31] M. D. T. P. Nasution and Y. Rossanty, "Country of Origin as a Moderator of Halal Label and Purchase Behavior,” J. Bus. Retail Manag. Res., vol. 12, no. 2, pp. 194-201, 2018.

[32] Jugdeep Kaur and Seema Baghla, Modified Decision Table Classifier By Using Decision Support and Confidence In Online Shopping Dataset. International Journal of Computer Engineering \& Technology, 8(6), 2017, pp. 83-88

[33] Dr. D. Sudhakar and R.Swarna Deva Kumari, Customer Satisfication towards Online Shopping: A Study with Reference to Chittoor District. International Journal of Management, 7(3), 2016, pp. 34-38.

[34] Dr .Anukrati Sharma, A Study on E - Commerce and Online Shopping: Issues and Influences, International Journal of Computer Engineering and Technology (IJCET), Volume 4, Issue 1, January- February (2013), pp. 364-376. 